\title{
A Clinical Study of Maternal and Fetal Outcome in Abruptio Placenta - Couvelaire Uterus a Preventable Obstetric Catastrophe
}

\author{
Vijayasree M
}

\begin{abstract}
Introduction : Hemorrhage is the single most important cause of maternal death worldwide. Obstetrical hemorrhage accounts for almost half of all postpartum deaths in developing countries. Among them Abruptio placenta occurs in around $1 \%$ of all pregnancies. Aim of this study was to determine the maternal and fetal outcome in pregnancy complicated by abruption placenta in relation to the risk factors.
\end{abstract}

Methods: This was a retrospective study conducted in the Department of Obstetrics and Gynecology, Mamata medical college, khammam from January 2010 to December 2014 for a period of five years. All pregnant women who were diagnosed with abruptio placenta after 28 weeks of gestation were included in the study. Patients were identified from the admission and labour room registers.

Results: Total number of deliveries during the study period were 4000 . Patients identified with abruptio placenta were 100 , giving a frequency of $2.5 \%$. Majority women were multigravidae and $56 \%$ of all the between $26-30$ years of age. The mean gestational age at diagnosis was $34 \pm 4.21$ weeks. Vaginal bleeding was the most common clinical finding seen in $80 \%$ of the women, followed by blood stained amniotic fluid in $16 \%$ suggesting concealed abruption placenta. Fetal heart sounds were absent on admission in $65 \%$ of the women. Most common cause of abruption $44 \%$ was either patients with past history of pre - eclampsia or PIH in the present pregnancy. 9 patients with couvelaire uterus were identified and treated effectively. Among them, two patients died due to postpartum hemorrhage. Parity and gestational age were found to be significant risk factors for abruptio placentae.

Conclusion: Abruptio placenta was associated with poor maternal and fetal outcomes. Early diagnosis and significant treatment of pre eclampsia during the antenatal period would prevent abruption and related complications.

Keywords: Abruption,couvelaire uterus,maternal and fetal outcome.

\section{INTRODUCTION}

Although medical advances have dramatically reduced the dangers of childbirth, death from hemorrhage, still remains a leading cause of maternal mortality especially in the developing countries. Hemorrhage is a direct cause of more than 17 percent of 4200 pregnancy-related maternal deaths in the United States as ascertained from the Pregnancy Mortality Surveillance System of

Department of Obstetrics Mamata general hospital, Khammam.,Andhra pradesh.

\section{Correspondence:}

Dr. M. Vijayasree.,MD

E-mail: hospitalstelangana@gmail.com

Competing interests: None the Centers for Disease Control and Prevention ${ }^{1}$. In many developed countries, hemorrhage is a leading reason for admission of pregnant women to intensive care units ${ }^{2,3,4,5}$. Indeed, hemorrhage is the single most important cause of maternal death worldwide. Obstetrical hemorrhage accounts for almost half of all postpartum deaths in developing countries ${ }^{6,7}$. Among them Abruptio placenta occurs in around $1 \%$ of all the pregnancies. ${ }^{8}$ Risk factors which have been found associated with Abruptio Placenta include maternal age, parity, smoking, hypertension, past history of Abruption, thrombophilic disorders, abdominal trauma and polyhydramnios. Abruptio placenta has been associated with poor maternal and fetal outcome like postpartum haemorrhage with its sequelae of acute tubular necrosis and disseminated intravascular coagulation, low birth weight babies, increased incidence of Prematurity and still birth." ${ }^{90}$ 10.The purpose of this study was to determine the risk factors,clinical presentation and outcome of pregnancies diagnosed with abruptio placenta. The aim of this study was to determine the maternal and fetal outcome in pregnancy complicated by abruption placenta in relation to the risk factors.

\section{METHODS}

This was a retrospective study conducted in the department of Obstetrics and Gynaecology , Mamata medical college, Khammam from January 2010 to December 2014 for a period of five years. All pregnant women who were diagnosed with abruptio placenta after 28 weeks of gestation were included in the study. Since ours is a referral centre many patients were unbooked without proper antenatal care and are usually admitted with complications. Patients were identified from the admission and labour room registers. Total number of deliveries during the study period were 4000 . Data was collected on a pre-designed Proforma for abruptio placenta. Placental abruption was defined as complete or partial separation of normally located placenta before delivery of the fetus. The diagnosis of placental abruption was made on clinical signs and symptoms of Blood loss per vaginam, tense and tender abdomen and confirmed at delivery by the local examination of placenta for separation and presence of retroplacental blood clots. Demographic variables which were collected for both group of women included maternal age, parity, past history of stillbirth and hypertension. Clinical and laboratory variables included bleeding per 
vaginam, blood stained amniotic fluid, maternal blood pressure, complete blood picture, serum urea and creatinine, Prothrombin time and partial thromboplastin time. Perinatal outcome which was noted included weight and gestational age of the baby and apgar score.Women with multiple pregnancy, fibroid uterus and polyhydramnios were excluded. The study was approved by ethical committee of our college. The data was collected and analyzed by using appropriate statistical methods.

\section{RESULTS}

A total of 100 cases were identified as abruptio placentae. Total number of deliveries during the study period were 4000 , giving an overall frequency of $2.5 \%$.

Table-1, 2 and 3 show the age, parity and the risk factor distribution of our study population. Majority $56 \%$ of the women were between 26-30 years of age group. 59\% women were either second, third or fourth gravida. The mean gestational age was $34 \pm 4.21$ weeks. $51 \%$ delivered preterm before 37 weeks and $49 \%$ delivered at or after 37 completed weeks of gestation. $10 \%$ women had history of previous stillbirth and $21 \%$ had history of gestational hypertension in previous pregnancies. Recurrent abruption was observed in $9 \%$ of the women.

Table-4, 5 shows the clinical characteristics and mode of delivery in the given population. Vaginal bleeding was the most common clinical finding seen in $80 \%$ of the women, blood stained amniotic fluid was seen in $16 \%$. Pre-labour, premature rupture of membranes was present in $7 \%$ and hypertension in current pregnancy was seen in $23 \%$. Fetal heart sounds were absent on admission in $65 \%$ of the patients. Spontaneous vaginal delivery occurred in $70 \%$ followed by caesarean section in $30 \%$ of the women. Postpartum hemorrhage (PPH) was seen in $18 \%$. Though there were 9 patients identified with couvelaire uterus, there were only 2 maternal deaths in the patients with couvelaire uterus in our study and both were due to atonic PPH. The mean fetal birth weight was $2400 \mathrm{~g}$. The perinatal mortality rate was $66 \%$. Retro placental blood clots, due to placental separation was associated with perinatal mortality. Perinatal loss was associated with a minimum of 200 $\mathrm{ml}$, and with no live birth at loss of $1000 \mathrm{ml}$ of blood loss since majority of our patients were anemic, even $200 \mathrm{ml}$ of blood loss was also trivial for that women and contributed to significant perinatal mortality.

TABLE-1 :DISTRIBUTION OF PATIENTS ACCORDING TO MATERNAL AGE ( $\mathrm{N}=100)$

\begin{tabular}{|l|l|l|}
\hline Maternal age (years) & No. of patients & percentage \\
\hline $20-25$ & 24 & $24 \%$ \\
\hline $26-30$ & 56 & $56 \%$ \\
\hline $31-35$ & 15 & $15 \%$ \\
\hline$>35$ & 5 & $5 \%$ \\
\hline
\end{tabular}

TABLE-2:DISTRIBUTION OF PATIENTS ACCORDING TO PARITY(N=100)

\begin{tabular}{|l|l|l|}
\hline Parity & No of patients & percentage \\
\hline Primigravida & 27 & $27 \%$ \\
\hline Multigravida(2-4) & 59 & $59 \%$ \\
\hline Grandmulti & 14 & $14 \%$ \\
\hline
\end{tabular}

TABLE-3:DISTRIBUTION OF PATIENTS ACCORDING TO THE RISK FACTORS ( $\mathrm{N}=100)$

\begin{tabular}{|l|l|l|}
\hline Risk factors & No. of patients & Percentage \\
\hline H/o previous still birth & 10 & $10 \%$ \\
\hline Previous h/o PIH & 21 & $21 \%$ \\
\hline Previous h/o abruption & 09 & $09 \%$ \\
\hline No h/o recurrent abruption & 60 & $60 \%$ \\
\hline
\end{tabular}

TABLE-4:DISTRIBUTION OF PATIENTS ACCORDING TO THE CLINICAL FEATURES ( $\mathrm{N}=100)$

\begin{tabular}{|l|l|l|}
\hline Clinical features & No of patients & Percentage \\
\hline Blood stained liquor & 16 & $16 \%$ \\
\hline Clear /meconium stained liquor & 54 & $54 \%$ \\
\hline Hypertention & 23 & $23 \%$ \\
\hline PROM & 7 & $7 \%$ \\
\hline
\end{tabular}


TABLE-5:DISTRIBUTION OF PATIENTS ACCORDING TO THE MODE OF DELIVERY(N=100)

\begin{tabular}{|l|l|l|}
\hline Mode of delivery & No of patients & Percentage \\
\hline Vaginal delivery & 70 & $70 \%$ \\
Normal delivery & 37 & $37 \%$ \\
\hline Instrumental & 15 & $15 \%$ \\
\hline Vaginal Breech delivery & 18 & $18 \%$ \\
\hline LSCS & 30 & $30 \%$ \\
\hline Total & 100 & $100 \%$ \\
\hline
\end{tabular}

\section{DISCUSSION:}

This study was conducted in a tertiary care referral centre with many patients referred from the peripheral hospitals. Review of literature showed that abruptio placenta complicates $1 \%$ of all the pregnancies. The frequency of Abruptio Placenta in our study group was $2.5 \%$. Sarwar et al, reported a prevalence of $4.4 \%$ in their population. ${ }^{11}$ Similar, high rates have been observed in studies from Abu-Heija A et al and Leunen $\mathrm{K}$ et al from Middle East. ${ }^{12,}{ }^{13}$. Studies from Ananth CV et al have taken maternal age $>35$ years as a significant risk factor for Abruptio Placenta. The incidence of abruption increases with maternal age. In the First and Second Trimester Evaluation of Risk (FASTER) trial, women older than 40 years were 2.3 times more likely to experience abruption compared with those 35 years or younger ${ }^{14}$.Our study did not show significant association of Abruption with maternal age. Grand multiparity has been found to be significantly associated with Abruption in a study done by Pritchard and co workers ${ }^{15}$, though we found it more commonly in third gravida. The study by Sarwar et al also had $49 \%$ of their population with parity between 1 and 4 . History of previous stillbirth and gestational hypertension was seen in $10 \%$ and $21 \%$ in our population. Ananth and associates reported a 2.4fold increased incidence of abruption with chronic hypertension, and this was increased further if there was superimposed preeclampsia or fetalgrowth restriction ${ }^{16}$. Zetterstrom and colleagues also reported a two fold increased incidence of abruption in women with chronic hypertension compared with normotensive women-an incidence of 1.1 versus
0.5 percent ${ }^{17}$ respectively. Both these factors are found to be significantly associated with Abruption. In our study, 9\% of women gave past history of Abruption. Past history of abruptio placenta was found to be associated with poor perinatal outcome $^{18}$.Toivonen et al, reported a recurrent abruption rate of $11.9 \%$, in women with previous history of Abruption ${ }^{19}$.Thus, it is recommended that in women with past history of Abruption, delivery should be considered between 34-37weeks of gestation, once the lung maturity has been documented. Bleeding per vaginum was present $80 \%$ of them and it was found to be the most common clinical manifestation of Abruption followed by blood stained amniotic fluid in 16\%. Similar results were also seen in a study by Tikkanen et al. Hurd and co-workers reported vaginal bleeding in 78 percent, uterine tenderness or back pain in 66 percent, and fetal distress in 60 percent of their patients ${ }^{20}$. The mean haemoglobin concentration was $7 \mathrm{gm} / \mathrm{dl}$, in our study population. This reflects poor nutritional status in our patients with iron and folic acid deficiency which is also a high risk factor for abruption. In another study from Asia, decreased body mass index, again reflecting poor nutritional status was found as an etiologic factor for Abruption ${ }^{21}$.Majority of our women, $70 \%$ had vaginal delivery followed by Caesarean section in 30\%. In study by Tikkanen et al, Caesarean section rate was as high as $91 \%$.We had two maternal deaths in our study group, both due to uncontrolled haemorrhage. They were referred late to the unit in shock. Both the patients had severe degree of couvelaire uterus followed by $\mathrm{PPH}$, they were managed with oxytocics after initial resuscitation followed by laparotomy .B- lynch procedure was applied, since both the patients were unstable, we attempted peripartum hysterectomy .In spite of our best efforts we lost these two patients .Both of these patients had gone into DIC which is usually seen in severe degree of concealed haemorrhage.

Perinatal mortality has been strongly associated with Abruptio Placenta in both national and international literature. Many studies from our Nation, found the perinatal mortality around 59\%. The high perinatal mortality rate was not due solely to placental abruption, but also to the associated increased incidence of preterm delivery and fetal-growth restriction. Nath and co-workers, however, reported that preterm birth was the overriding association with these low-birthweight babies.

In the above study, there were a total of $54(65 \%)$ fetal deaths. Statistical analysis in our study showed significant association of fetal deaths with gestational age. Increased perinatal mortality was seen with preterm gestation. In our study, the association was found much stronger for moderately preterm gestation in conflict with Ananth study, where association was far stronger with very preterm gestation. This may be attributed to sample size as well as different limits in salvaging the babies in our setup. The mean birth weight was found to be $2400 \mathrm{~g}$. In a study by Nath et al, among abruption cases, $60.3 \%(\mathrm{n}=94)$ were low birth weight in comparison with $11.2 \%(\mathrm{n}=19)$ of controls. This was attributed to the gestational age, and ruled out other confounders like thrombophilia. 
Abruptio placenta is a catastrophic obstetrical condition, commonly seen in our hospital. Prevalence of this disease is higher in our set-up, since ours is a referral centre and lot of patients with high risk factors do get admitted in our labour room. This condition can be prevented with good antenatal care, early diagnosis and treatment of risk conditions that can cause abruption. No definite etiological factor has been identified; neither the disease can be predicted with good sensitivity and specificity. The rate of recurrence in subsequent pregnancies is higher and is also associated with poor prognosis. Recently, use of low molecular weight heparin has been found to improve pregnancy outcome in women who are at risk for recurrent abruption, irrespective of thrombophilia status. ${ }^{22}$ There may be a role of heparin in improving pregnancy outcome in diseases involving the utero-placental interface. ${ }^{23}$ Though, this needs to be tested in large randomized trials.

\section{CONCLUSION}

Abruptio placenta is associated with poor maternal and fetal outcome. It may recur in subsequent pregnancy. Improved nutritional status, antenatal care and delivery between 3437 weeks of gestation, once lung maturity is established, may improve outcome in subsequent pregnancies. couvelaire uterus and subsequent PPH can be prevented by termination of pregnancy as soon as abruption is diagnosed especially concealed variety.

\section{REFERENCES}

1. Gerberding JL: Centers for Disease Control and Prevention: Update: Pregnancy-related mortality ratios, by year of death-United States, 1991-1999.
MMWR 52:1, 2003.

2. Gilbert TT, Smulian JC, Martin AA, et al: Obstetric admission to the intensive care unit: Outcomes and severity of illness. Obstet Gynecol 102:897, 2003.

3. Hazelgrove JF, Price C, Pappachan VJ, et al: Multicenter study of obstetric admissions to 14 intensive care units in southern England. Crit Care Med 29:770, 2001.

4. Zeeman GG, Wendel Jr GD, Cunningham FG: A blueprint for obstetric critical care. Am J Obstet Gynecol 188:532, 2003.

5. Zwart JJ, Richters JM, Öry F, et al: Severe maternal morbidity during pregnancy, delivery and puerperium in the Netherlands: A nationwide populationbased study of 371,000 pregnancies. BJOG 115:842, 2008.

6. Lalonde A, Daviss BA, Acosta A, et al: Postpartum hemorrhage today: ICM/FIGO initiative 2004-2006. Int J Obstet Gynaecol 94:243, 2006.

7. McCormick ML, Sanghvi HC, Mclntosh N: Preventing postpartum hemorrhage in lowresource settings. Int J Gynaecol Obstet 77:267, 2002.

8. Ananth CV, Savitz DA, Williams MA. Placental abruption and its association with hypertension and prolonged rupture of membranes: a methodologic review and meta-analysis. Obstet Gynecol 1996; 88: 309-18.

9. Nath CA, Ananth CV, DeMarco C, Vintzileos AM, New Jersey-Placental Abruption Study Investigators. Low birthweight in relation to placental abruption and maternal thrombophilia status. Am J Obstet Gynecol 2008; 198: 293 e1-5.

10. Ananth CV, Berkowitz GS, Savitz DA, Lapinski RH. Placental abruption and adverse perinatal outcomes. JAMA 1999; 282: 1646-51.

11. Sarwar I, Abbasi AN, Islam A. Abruptio placentae and its complications at Ayub Teaching Hospital Abbottabad. J Ayub Med Coll Abbottabad 2006; 18: 27-31.

12. Abu-Heija $A$, al-Chalabi $H$, el-lloubani N. Abruptio placentae: risk factors and perinatal outcome. J Obstet Gynaecol Res 1998; 24: 141-4.

13. Leunen $\mathrm{K}$, Hall DR, Odendaal HJ, Grove D. The profile and complications of women with placental abruption and intrauterine death. J Trop Pediatr 2003; 49: 231-4.

14. Cleary-Goldman J, Malone FD, Vidaver J, et al: Impact of maternal age on obstetric outcome. Obstet Gynecol 105:983, 2005.

15. Pritchard JA, Cunningham FG, Pritchard $S A$, et al: On reducing the frequency of severe abruptio placentae. Am J Obstet Gynecol 165:1345, 1991.

16. Ananth CV, Peltier MR, Kinzler WL, et al: Chronic hypertension and risk of placental abruption: Is the association modified by ischemic placental disease? Am J Obstet Gynecol 197:273.e1, 2007.

17. Zetterstrom K, Lindeberg SN, Haglund B, et al: Maternal complications in women with chronic hypertension: A populationbased cohort study. Acta Obstet Gynecol Scand 84:419, 2005.

18. Matsaseng T, Bagratee JS, Moodley J. Pregnancy outcomes in patients with previous history of abruptio placentae. Int J Gynaecol Obstet 2006; 92: 253-4.

19. Toivonen S, Heinonen S, Anttila M, Kosma VM, Saarikoski S. Obstetric prognosis after placental abruption. Fetal Diagn Ther 2004; 19: 336-41.

20. Hurd WW, Miodovnik M, Hertzberg V, et al: Selective management of abruptio placentae: A prospective study. Obstet Gynecol 61:467, 1983.

21. Hung TH, Hsieh CC, Hsu JJ, Lo LM, Chiu $\mathrm{TH}$, Hsieh TT. Risk factors for placental abruption in an Asian population. Reprod Sci 2007; 14: 59-65.

22. Rey E, Garneau P, David M, Gauthier R, Leduc L, Michon N, et al. Dalteparin for the prevention of recurrence of placentalmediated complications of pregnancy in women without thrombophilia: a pilot randomized controlled trial. J Thromb Haemost 2009; 7: 58-64.

23. Hossain N, Paidas MJ. Adverse pregnancy outcome, the uteroplacental interface, and preventive strategies. Semin Perinatol 2007; 31: 208-12. 